\title{
ANÁLISE DO TAMANHO, NÚMERO E VOLUME DE PARTÍCULAS TRITURADAS DURANTE A MASTIGAÇÃO ATRAVÉS DA EQUAÇÃO DE ROSIN-RAMMLER
}

Alfonso SÁNCHEZ-AYALA; Ana Paula FRANCO; Eloísa de PAULA; João Carlos GOMES; Osnara Maria Mongruel GOMES

O propósito deste estudo foi analisar o tamanho, número e volume das partículas trituradas durante a mastigação. Utilizou-se uma amostra de 30 indivíduos saudáveis, 15 homens e 15 mulheres, de 20 a 25 anos de idade com dentição completa. Para a análise utilizou-se o método de Peneirada Múltipla Vibratória com peneiras de 11.2 a $0.5 \mathrm{~mm}$ de abertura e um alimento de prova artificial de silicone Optosil $\AA_{\text {de }} 20 \mathrm{~mm}$ de diâmetro e $5 \mathrm{~mm}$ de espessura. A distribuição das partículas trituradas resultantes foi analisada através da equação de Rosin-Rammler. O teste t foi empregado para a análise estatística. A mediana do tamanho, volume e número de partículas obtidas até 20 ciclos mastigatórios para a amostra analisada foi de $4,392 \mathrm{~mm}, 0.231 \mathrm{~mm} / \mathrm{mm}$ e $12.8281 \mathrm{~mm}-\mathrm{xmm}$, respectivamente. A mediana do tamanho de partícula foi de $4.391 \mathrm{~mm}$ para o sexo masculino, e de 4.385 para o sexo feminino. Não houve diferença significativa nas porcentagens de peso retido e peso acumulado para ambos os sexos $(p>0.05)$. A distribuição de partículas trituradas durante a mastigação pode ser analisada satisfatoriamente através da equação de Rosin-Rammler. 